\title{
Перспективы автомобилизации в Евросоюзе и Китае при различных сценариях распространения беспилотных совместно используемых автомобилей
}

М.Ю. КСЕНОФОНТОВ, дОктор эКономических наук,

C.P. МИляКИН, Институт народнохозяйственного прогнозирования $\mathrm{PAH,}$ Москва. E-mail: milyakin90@mail.ru

Статья посвящена прогнозу динамики парка легковых автомобилей при различных сценариях распространения их совместного использования и технологий автоматизации процесса управления ими. Дается описание сценариев, инструментария вариантных сценарных прогнозных расчетов, а также их результатов для Евросоюза и Китая. Они демонстрируют, что в перспективе 25-30 лет эти социальные и технологические инновации способны оказать существенное влияние на траекторию показателей обеспеченности населения и общего парка легковых автомобилей. Под действием новых факторов динамика этих показателей будет описываться кривой, имеющей «пик», т.е. максимальное значение, после достижения которого будет наблюдаться не стабилизация, как в рамках традиционного подхода к моделированию процессов автомобилизации с использованием S-образных функций, а масштабный спад.

Актуальность исследования для прогнозирования российской экономики связана, во-первых, с тем, что автомобилизация в мире во многом определяет перспективы потребления и экспорта энергоносителей, во-вторых, отмеченные тенденции автомобилизации, вероятно, будут наблюдаться и в нашей стране. Ключевые слова: автомобилизация, совместное использование, беспилотные автомобили, сценарные расчеты, долгосрочный прогноз

При построении долгосрочного прогноза процессов автомобилизации (процесса накопления и воспроизводства парка легковых автомобилей как в собственности домохозяйств, так и коммерческих, удовлетворяющих потребности населения в пассажирских перевозках) исследователи традиционно рассматривают показатель обеспеченности населения легковыми автомобилями (на 1000 чел.) [Jong G. et al, 2004], причем в большом числе работ для его описания и моделирования используются S-образные кривые: логистическая функция [Tanner, 1975; Debabrata et al, 2010; Эткин, 2009], функция Гомпертца [Dargay et al, 2007; Нао et al, 2011; Wu et al, 2014; Эдер и др., 2017], квазилогистическая 
функция [Button et al, 1993], кривая силового роста [Tanner 1977, 1983]. Связано это, в первую очередь, с предположением, что на поздних этапах автомобилизации темпы прироста обеспеченности будут замедляться (рис. 1).

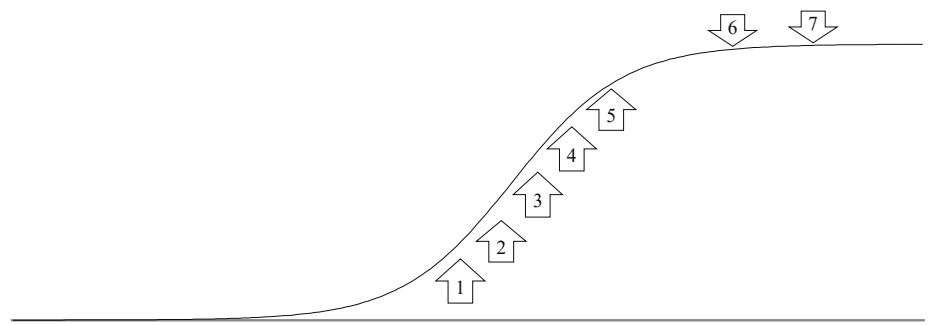

Puc. 1. Графический образ процесса автомобилизации в рамках традиционного подхода

Факторы автомобилизации: 1) динамика доходов, 2) формирование вторичного рынка автомобилей, 3) развитие автомобилестроения и 4) финансового сектора, 5) формирование развитых международных автомобильных рынков, 6) пространственные и 7) экологические ограничения.

Такая особенность динамики показателя числа легковых автомобилей на 1000 чел., свойственная ряду развитых стран (рис. 2), обычно объясняется феноменом насыщения потребности [Jong G. et al, 2004].

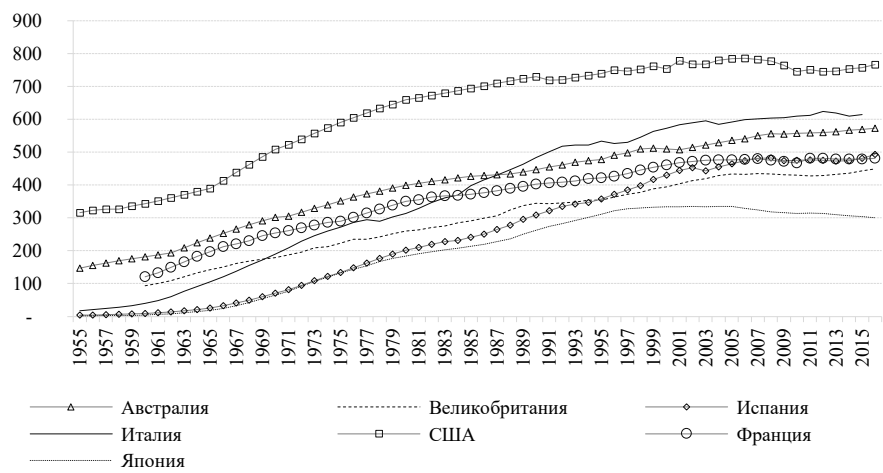

Puc. 2. Число легковых автомобилей на 1000 чел. в некоторых странах мира в 1955-2015 гг., ед. 
Однако последние данные об удельном спросе на поездки с использованием легкового автомобильного транспорта свидетельствуют о том, что автомобилизация может относиться к процессам, характеризующимся пиком [Goodwin, 2012]. Обеспеченность населения легковыми автомобилями на этапе зрелой автомобилизации не стабилизируется на постоянном уровне, а начинает снижаться, в частности, в Японии это наблюдается с 2005 г. (см. рис. 2). Это обусловлено негативными социальными и экологическими последствиями автомобилизации, мерами экологической политики, а также снижением престижа владения автомобилем среди молодежи, распространением электронной торговли, удаленной работы, мобильного Интернета и социальных сетей [Goodwin, 2012].

Кроме того, с точки зрения построения прогноза в долгосрочной перспективе важными оказываются относительно новые факторы: распространение практик совместного использования автомобилей (краткосрочная аренда, сервисы такси, организованные с помощью мобильных приложений, поездки с попутчиками) и беспилотного ${ }^{1}$ автомобильного транспорта (обладающего значительным потенциалом совместного использования) [Ксенофонтов и др., 2018]. Механизм воздействия этих факторов заключается в том, что один легковой автомобиль, участвующий в совместном использовании, способен удовлетворить потребности в перевозках существенно более широкого круга людей, что сокращает их общий парк в собственности домашних хозяйств. А беспилотный автомобиль, интегрированный в сеть, взаимодействующий с другими автомобилями и инфраструктурой, имеет еще больший потенциал «замещения» традиционных автомобилей [Arbib et al, 2017]. Речь идет как о выборе оптимального маршрута (уменьшение числа пробок и времени в пути), так и о возможности совместного использования беспилотного автомобиля как в пределах одного домашнего хозяйства, так и среди клиентуры мобильного приложения.

На рисунке 3 приведены механизмы формирования уровня обеспеченности автомобилями с учетом факторов, под действием которых автомобилизация может рассматриваться как процесс, имеющий «пик», а не «уровень насыщения».

\footnotetext{
${ }^{1}$ Беспилотные, или полностью автономные автомобили - те, в которых функции вождения и контроля осуществляются преимущественно интеллектуальной системой, а не водителем.
} 


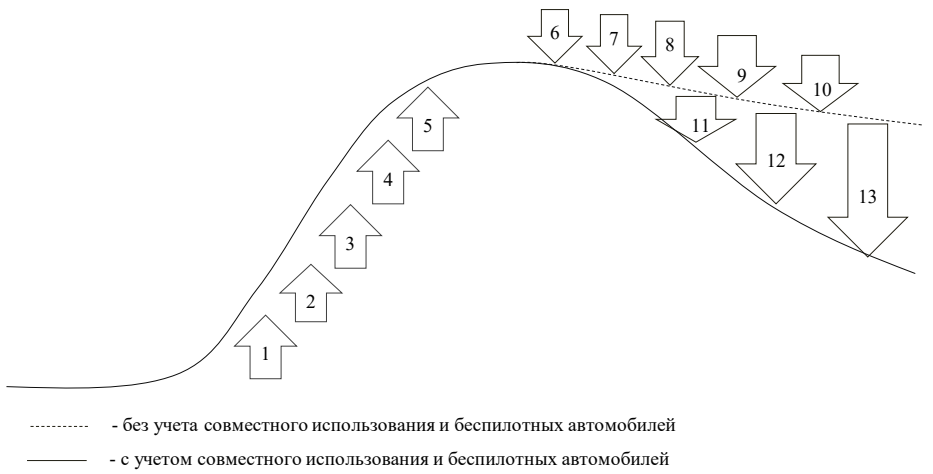

Puc. 3. Графический образ процесса автомобилизации в рамках подхода, который рассматривает ее не как «процесс с насыщением», а как «процесс с пиком»

Факторы автомобилизации: 1) динамика доходов, 2) формирование вторичного рынка автомобилей, 3) развитие автомобилестроения и 4) финансового сектора, 5) формирование развитых международных автомобильных рынков, 6) пространственные и 7) экологические ограничения, 8) снижение престижа владения автомобилем, 9) эволюция расселения, 10) распространение Интернета, 11) совместное использование автомобилей, 12) внедрение беспилотных автомобилей, 13) формирование на базе беспилотников автомобилей нового сектора индивидуализированного общественного транспорта.

\section{Инструментарий прогнозных расчетов}

Расчеты проводятся в два этапа. На первом оценивается потенциальная потребность в услугах легкового автотранспорта в зависимости от динамики экономического развития и численности населения. На втором - полученные оценки динамики и объемов автомобильного парка корректируются с учетом гипотез о темпах распространения совместного использования автомобилей и достижимого уровня автоматизации процессов управления ими. В качестве сценарных параметров на втором этапе расчетов выступают: доля беспилотных автомобилей в совокупных продажах легковых автомобилей в стартовой точке (2025 г.); темп прироста 
их продаж; число традиционных ${ }^{2}$ автомобилей, замещаемых одним полностью автономным совместно используемым автомобилем в продажах; доля выбытия традиционных автомобилей.

Ввиду того, что автомобильный транспорт является крупным потребителем нефтепродуктов, модель была дополнена расчетом структуры парка легковых автомобилей по видам двигателей (двигатель внутреннего сгорания/электродвигатель) в зависимости от гипотез их доли в продажах.

Иллюстративный расчет был выполнен для Евросоюза, находящегося на позднем этапе автомобилизации, и Китая (начальный этап). Было рассмотрено шесть сценариев распространения полностью автономных автомобилей и их совместного использования. При этом в них приняты одинаковые гипотезы в отношении внедрения электромобилей (табл. 1), которые основываются на уже сформулированных целевых установках государственных и городских властей [Анисимов, 2017].

\section{Таблица 1. Доля электромобилей в совокупных продажах легковых автомобилей в рассматриваемых сценариях в 2015-2045 гг., \%}

\begin{tabular}{|l|c|c|c|c|}
\hline \multicolumn{1}{|c|}{ Регион } & $\mathbf{2 0 1 5}$ & $\mathbf{2 0 2 5}$ & $\mathbf{2 0 3 5}$ & $\mathbf{2 0 4 5}$ \\
\hline ЕС & 1 & 15 & 45 & 75 \\
\hline Китай & 1 & 10 & 30 & 50 \\
\hline
\end{tabular}

\section{Сценарии и результаты прогнозных расчетов}

\section{Сценарий 1 (инерциионный)}

На данный момент системы, позволяющие водителю не принимать участие в вождении и контроле, разработаны и проходят стадию тестирования, однако на пути их массового использования могут возникнуть существенные барьеры, в частности, следующие.

- Полная автономность окажется технически недостижимой.

- Система полностью автономного вождения повысит себестоимость настолько, что единственной нишей для автомобилейбеспилотников окажется премиальный сегмент.

- Технически недостижимым окажется обеспечение безопасности данных (информации) пользователей и/или защита

2 Под традиционными понимаются автомобили, которые находятся во владении домохозяйств и используются единолично. Сюда относятся как автомобили без автопилота, так и полуавтономные (функции вождения и контроля осуществляются преимущественно водителем, но в определенных условиях возможно автопилотирование). 
системы управления от взлома и внешнего контроля. У полностью автономного автомобиля (в том числе для снижения вероятности столкновения) функции вождения и контроля за движением осуществляются не водителем, а автопилотом, подключенным к сети и постоянно принимающим и передающим данные. Естественным следствием невозможности защитить эти данные или систему управления от взлома может быть либо запрет на использование таких систем со стороны органов государственного управления, либо отказ потенциальных пользователей от их покупки и эксплуатации. Даже низкая вероятность взлома для рядового пользователя может стать источником недоверия к новой технологии и чувства беспокойства за свою жизнь и здоровье. В таких условиях спрос на полностью беспилотные автомобили может быть пренебрежимо малым.

- Обеспечение безопасности данных пользователей и/или защита системы управления от взлома и внешнего контроля повысит себестоимость автомобиля до уровня премиального сегмента.

- Угроза высвобождения значительных трудовых ресурсов (водители) и социальной напряженности, особенно в развивающихся странах. При отсутствии государственной политики по организации переобучения водителей [Hawksworth et al, 2018] рост социальной напряженности может привести к ограничению распространения беспилотного совместно используемого транспорта. Например, в Индии правительство уже заявило о таком решении [Индия не разрешит, 2017].

Труднопреодолимые препятствия на пути внедрения беспилотных автомобилей могут привести к тому, что не произойдет технологического толчка, стимулирующего практику совместного использования внутри домохозяйств и развитие специализированных сервисов, процесс автомобилизации останется инерционным. Сейчас совокупный парк совместно используемых автомобилей в США (включая аренду автомобилей, принадлежащих домашним хозяйствам и специализированным компаниям) составляет около 149 тыс. ед. (не более 0,07\% от совокупного); общее число пользователей - около 4,3 млн чел. (не выше 1,5\%). При этом темпы роста сферы совместного использования впечатляющие: в 2016 г. парк вырос на 80\%, число пользователей - на 58\% [Shaheen et al, 2018]. Однако, если беспилотные автомобили не будут технологическим драйвером, эти темпы, характерные только для начальных 
этапов, станут снижаться, и совместное использование останется нишевой практикой. Полуавтономные автомобили, доля которых в парке, вероятно, будет расти, не создают новых стимулов для распространения совместного использования. Все эти обстоятельства позволяют сформулировать главную черту сценария 1: в нем сохраняется традиционная логика воспроизводства парка легковых автомобилей (табл. 2).

\section{Таблица 2. Численное значение параметров в сценарии 1}

\begin{tabular}{|l|c|}
\hline \multicolumn{1}{|c|}{ Параметр } & Значение \\
\hline $\begin{array}{l}\text { Доля беспилотныхсовместноиспользуемыхавтомобилей } \\
\text { в продажах в 2025 г.,\% }\end{array}$ & 0 \\
\hline $\begin{array}{l}\text { Темпы прироста продаж беспилотных совместно исполь- } \\
\text { зуемых автомобилей,\% }\end{array}$ & 0 \\
\hline Степень замещения & 1 \\
\hline Выбытие традиционных автомобилей,\% & Как в ретроспективе (7) \\
\hline
\end{tabular}

Примечание. Степень замещения - число легковых автомобилей, используемых единолично, замещаемых одним беспилотным совместно используемым автомобилем.

Расчеты показывают, что в сценарии 1 объем парка легковых автомобилей в Евросоюзе возрастет к 2045 г. до 284 млн ед. (на 9\% к 2017 г.). В Китае, где автомобилизация находится на относительно низком уровне ${ }^{3}$, рост более значительный: в 2,9 раза (525 млн ед.). При принятых гипотезах распространения электромобилей (см. табл. 1) к 2045 г. их доля в Евросоюзе составит 42\% (120 млн ед.), в Китае - 24\% (163 млн ед.).

\section{Сиенарий 2 (консервативный)}

По заявлениям автопроизводителей, полностью автономные автомобили появятся к 2021-2022 гг., некоторое время понадобится на их тестирование и продвижение. В связи с этим большинство экспертов ожидают массового внедрения беспилотных автомобилей с 2025 г. [Marshall, 2017; Lenardi, 2017] . В сценарии 2 предполагается, что возможные препятствия, описанные в сценарии 1, успешно преодолеваются, и доля беспилотных автомобилей в продажах становится значимой в 2025 г. (табл. 3).

\footnotetext{
${ }^{3}$ В 2017 г. на 1000 чел. в Китае приходилось около 128 легковых автомобилей, в то время как в развитых странах - от 400 до 780 .

${ }^{4}$ Hyundai Says Not So Fast on Self-Driving Car. Available at: http://www. industryweek.com/emerging-technologies/hyundai-says-not-so-fast-self-driving-car (accessed 28.02.2018).
} 
Таблица 3. Численное значение параметров в сценарии 2 в 2025 r., 2035 r., 2045 r.

\begin{tabular}{|l|c|c|c|}
\hline \multicolumn{1}{|c|}{ Параметр } & $\mathbf{2 0 2 5}$ & $\mathbf{2 0 3 5}$ & $\mathbf{2 0 4 5}$ \\
\hline $\begin{array}{l}\text { Доля беспилотных совместно используемых } \\
\text { автомобилей в продажах в 2025 г.,\% }\end{array}$ & 1 & & \\
\hline $\begin{array}{l}\text { Темпы прироста продаж беспилотных совместно } \\
\text { используемых автомобилей,\% }\end{array}$ & 50 & 10 & 1 \\
\hline Степень замещения & 1 & 2 & 4 \\
\hline Выбытие традиционных автомобилей,\% & 7 & 7 & 7 \\
\hline
\end{tabular}

В рамках этого сценария принимается предположение, что полностью автономные автомобили продаются только специализированным компаниям и/или становятся частью парка каршеринговых компаний, созданных самими автопроизводителями, и не продаются в личное пользование домохозяйств. Это может быть связано с тем, что при продаже беспилотных автомобилей в личное пользование возникают проблемы разграничения ответственности в случае возникновения аварий [Brodsky, 2016]. В частности, подобный сценарий рассматривается в рекомендациях по транспортной политике в провинции Онтарио [Grush et al, 2016]. Парк личных автомобилей формируется за счет традиционных, в том числе полуавтономных, которые не расширяют возможностей совместного использования. Полуавтономные автомобили с течением времени могут становиться все более комфортными и при этом оставаться под контролем водителя. Это обеспечивает их конкурентоспособность по отношению к полностью беспилотным и ограничивает потенциал роста рынка совместного использования на базе беспилотных автомобилей. Эти обстоятельства, с одной стороны, предопределяют более высокие темпы проникновения беспилотных совместно используемых автомобилей по сравнению со сценарием 1. С другой стороны, распространение беспилотных автомобилей (а значит, и их возможность замещения традиционных) ограничено рамками специализированных сервисов, а большинство потребителей не готовы отказаться от владения автомобилем [Дорога в будущее, 2018].

Стоит отметить, что массовая эксплуатация полуавтономных автомобилей значительно снижает безопасность на дорогах даже по сравнению с транспортом, не оснащенным системой автопилотирования, поскольку водители склонны полагаться на автопилот, и в критической ситуации не успевают взять 
управление на себя. Это является значимым стимулом как для автопроизводителей, так и для государственных властей с целью ограниченного внедрения полуавтономных и поощрения разработок полностью беспилотных автомобилей [Higgins et al, 2018].

Таким образом, основные отличия сценария 2 от сценария 1 состоят в том, что происходит внедрение беспилотников, которое способствует развитию совместного использования и сокращению потребности в автомобилях, приобретаемых в собственность домашних хозяйств, а потенциал сокращения потребности в традиционных автомобилях ограничивается вследствие того, что беспилотные получают распространение преимущественно в специализированных сервисах. Расчеты показывают, что это приводит к снижению совокупного парка легковых автомобилей по сравнению со сценарием 1 в Евросоюзе на 91 млн ед., в Китае на 173 млн ед. В Евросоюзе парк легковых автомобилей достигает пика к 2030 г. (279 млн ед.), затем снижается до 193 млн ед. к 2045 г. (на 26\% меньше, чем в 2017 г.). В Китае объем парка достигает пика к 2036 г. (444 млн ед.), затем снижается до 352 млн ед. (на 95\% больше, чем в 2017 г.). При принятых гипотезах распространения электромобилей (см. табл. 1) в сценарии 2 к 2045 г. их доля в Евросоюзе составит 34\% (65 млн ед.), в Китае - 27\% (94 млн ед.).

\section{Сиенарий 3.1 (сохранение традицичонной мобильности)}

В нем, как в сценарии 2, принимается гипотеза, что массовое внедрение беспилотных автомобилей начнется с 2025 г. Предполагается, что проблемы разграничения ответственности между владельцем автомобиля и его производителем при авариях будут разрешены, что снимет ограничение на продажу беспилотников в личное пользование, действующее в сценарии 2.

Есть аргументы и в пользу того, что у большинства потребителей будут мотивы и необходимость владеть собственными автомобилями. Во-первых, спрос на них велик в сельской местности, где автомобили, принадлежащие специализированным компаниям, не столь эффективны (особенно в части времени ожидания), и этот спрос может распространяться и на беспилотники. Во-вторых, полностью автономные автомобили будут стоить меньше, чем традиционные: снижение вероятности столкновения обусловит снижение их веса и экономию на используемых материалах; полная автономность также позволит сэкономить на 
оснащении интерфейсом связи с водителем (руль, педали, приборная панель). Кроме того, один и тот же автомобиль-беспилотник может использоваться всеми членами одного домохозяйства (то есть заменять несколько традиционных), что позволит существенно сэкономить. В-третьих, полностью автономные автомобили будут в еще большей степени использоваться для отдыха и работы, а потому потребители захотят оставлять и хранить в них личные вещи, что невозможно в такси [Kurman et al, 2018].

В сценарии 3.1 принимается гипотеза, что полностью автономные автомобили будут продаваться не только специализированным компаниям, но и домохозяйствам. Параметры выбытия традиционных автомобилей задаются возрастающими (в отличие от сценариев 1 и 2), в предположении, что люди будут быстрее отказываться от традиционных автомобилей в пользу более комфортных и экономичных полностью автономных.

В сценарии 3.1 также принимается гипотеза о том, что повышенная эффективность и принципиально новый уровень комфорта будут стимулировать возрастающий спрос на беспилотные автомобили, что определяет более высокие темпы роста их продаж по сравнению со сценарием 2. Кроме того, ввиду активной государственной и городской интермодальной ${ }^{5}$ транспортной политики в данном сценарии предполагается, что общественный транспорт обладает экономическими преимуществами по сравнению с беспилотными автомобилями (как в составе такси, так и в личном пользовании); его качество, доступность и престиж постоянно растут; беспилотники не конкурируют, а дополняют общественный транспорт. Поэтому основной спрос на беспилотные автомобили формируется со стороны не пользователей общественного транспорта, а автомобилистов.

Также принимается гипотеза о том, что беспилотные автомобили, находящиеся в собственности домохозяйств, будут использоваться совместно. В настоящее время на одно домохозяйство в развитых странах приходится два автомобиля. Для отдельного домохозяйства беспилотный автомобиль, способный самостоятельно возвращаться домой, развозить всех членов семьи, является

\footnotetext{
${ }^{5}$ Интермодальная транспортная политика направлена на выстраивание транспортной системы, в которой большинство жителей используют в своих ежедневных поездках несколько видов транспорта, и личный транспорт дополняет общественный, а не заменяет его [Вучик, 2011].
} 
более комфортной и более экономичной (ведь он заменяет сразу два автомобиля) альтернативой традиционному. Если же беспилотный автомобиль используется в рамках нескольких домохозяйств, связанных родственными, дружескими, соседскими отношениями, то экономические преимущества еще выше. Гипотезы относительно способов использования одного и того же автомобиля позволяют сформулировать ориентиры для задания степени замещения. Если большая часть беспилотных автомобилей используется эффективно в рамках одного домохозяйства, то степень замещения должна быть примерно равна двум. Если один и тот же автомобиль используется сразу несколькими домохозяйствами, то степень замещения возрастает. Однако потенциал эффективности беспилотных автомобилей в сценарии 3.1 ограничен сохранением традиционного режима мобильности. Если в сценариях 1 и 2 влияние возможных изменений в режимах мобильности было несущественным из-за слабого развития сферы беспилотного совместно используемого транспорта, то в сценарии 3.1 сохранение традиционной мобильности становится важным условием при оценке параметра замещения традиционных автомобилей совместно используемыми беспилотниками.

В настоящее время ежедневная мобильность имеет два пикаутренний и вечерний. Если ситуация сохранится, то беспилотные автомобили (даже будучи более эффективными в маневрировании и организации движения по сравнению с традиционными и используемые совместно в качестве аналога такси или обслуживая нескольких членов одного/двух домохозяйств) тем не менее окажутся на дорогах одновременно, а потому максимальный уровень замещения определяется как раз в часы пик. Один традиционный легковой автомобиль в среднем вмещает четырех человек, а потому максимальное число легковых автомобилей, которое мог бы заместить беспилотник, равняется четырем. В остальные часы дня часть полностью автономных автомобилей будет простаивать, a, значит, их потенциал будет использован не полностью.

Таким образом, в сценарии 3.1 предполагается, что к 2035 г. средняя степень замещения достигнет двух, а к 2045 г. - четыpex (что эквивалентно гипотезе о том, что личные беспилотные автомобили используются в среднем двумя домохозяйствами). То обстоятельство, что не все домохозяйства смогут использовать беспилотные автомобили совместно, будет компенсироваться тем, 
что часть из них используется в качестве такси (то есть большим количеством домохозяйств, в том числе тех, которые отказались от покупки автомобиля в собственность).

\section{Таблица 4. Численное значение параметров в сценарии 3.1 в 2025 r., 2035 r., 2045 r.}

\begin{tabular}{|l|c|c|c|}
\hline \multicolumn{1}{|c|}{ Параметр } & $\mathbf{2 0 2 5}$ & $\mathbf{2 0 3 5}$ & $\mathbf{2 0 4 5}$ \\
\hline $\begin{array}{l}\text { Доля беспилотных совместно используемых автомо- } \\
\text { билей в продажах в 2025 г.,\% }\end{array}$ & 2 & & \\
\hline $\begin{array}{l}\text { Темпы прироста продаж беспилотных совместно } \\
\text { используемых автомобилей,\% }\end{array}$ & 60 & 15 & 2 \\
\hline Степень замещения & 1 & 2 & 4 \\
\hline Выбытие традиционных автомобилей,\% & 7 & 10 & 13 \\
\hline
\end{tabular}

Итак, основное отличие сценария 3.1 от сценария 2 состоит в том, что беспилотные автомобили продаются домохозяйствам и используются ими совместно. В рамках принятых гипотез расчеты показывают, что совместное использование беспилотников не только в рамках специализированных сервисов, но и внутри домохозяйств приводит к снижению совокупного парка легковых автомобилей в Евросоюзе по сравнению со сценарием 1 на 173 млн по сравнению со сценарием 2 - на 82 млн ед.; снижению совокупного парка легковых автомобилей в Китае по сравнению со сценарием 1 на 335 млн по сравнению со сценарием 2 - на 162 млн ед. В Евросоюзе парк легковых автомобилей достигает пика к 2028 г. (278 млн ед.), затем снижается до 111 млн ед. (на 57\% меньше, чем в 2017 г.); в Китае объем парка достигает пика к 2033 г. (414 млн ед.), затем снижается до 190 млн ед. (на 5\% больше, чем в 2017 г.). В принятых гипотезах распространения электромобилей (см. табл. 1) в сценарии 3.1 к 2045 г. их доля в Евросоюзе составит 42\% (47 млн ед.), в Китае - 33\% (62 млн ед.).

\section{Сиенарий 3.2 (изменение режима мобильности)}

Основное его отличие от сценария 3.1 состоит в том, что пики мобильности сглажены, и транспортные потоки более равномерно распределятся в течение дня вследствие развития удаленной работы, гибкого графика, фриланса ${ }^{6}$.

\footnotetext{
${ }^{6}$ Параметры мобильности могут кардинально измениться в связи с роботизацией производства и сферы услуг, которые приведут к фундаментальной трансформации рынка труда и занятости [Hawksworth, 2018]. Эти изменения могут активизировать факторы как снижения потребности в транспортных услугах, так и ее роста, но в данной работе эти эффекты не рассматриваются.
} 
В условиях распределенной мобильности снимаются ограничения на степень замещения, описанные в сценарии 3.1 . Один и тот же беспилотный автомобиль может использоваться многократно в течение дня членами разных домохозяйств, соответственно, степень замещения может быть существенно выше четырех. В рамках личного владения это возможно за счет расширения круга домохозяйств, имеющих доступ к беспилотному автомобилю, и сдачи его в аренду (с помощью мобильных приложений, по аналогии с Uber). В результате степень замещения традиционных автомобилей беспилотными совместно используемыми достигнет восьми (во столько раз в среднем транспортная работа современного такси выше, чем личного автомобиля).

\section{Таблица 5. Численное значение параметров в сценарии 3.2} в 2025 r., 2035 r., 2045 r.

\begin{tabular}{|l|c|c|c|}
\hline \multicolumn{1}{|c|}{ Параметр } & $\mathbf{2 0 2 5}$ & $\mathbf{2 0 3 5}$ & $\mathbf{2 0 4 5}$ \\
\hline $\begin{array}{l}\text { Доля беспилотных совместно используемых автомо- } \\
\text { билей в продажах в 2025 г.,\% }\end{array}$ & 2 & & \\
\hline $\begin{array}{l}\text { Темпы прироста продаж беспилотных совместно } \\
\text { используемых автомобилей,\% }\end{array}$ & 60 & 15 & 2 \\
\hline Степень замещения & 1 & 4 & 8 \\
\hline Выбытие традиционных автомобилей,\% & 7 & 10 & 13 \\
\hline
\end{tabular}

Расчеты по сценарию 3.2 показывают, что более эффективное использование автомобилей-беспилотников, обусловленное сглаживанием утренних и вечерних пиков интенсивности дорожного движения, приводит к снижению совокупного парка легковых автомобилей в Евросоюзе по сравнению со сценарием 1 на 205 млн по сравнению со сценарием 3.1 - на 32 млн ед. В Китае совокупный парк легковых автомобилей по сравнению со сценарием 1 уменьшится на 397 млн со сценарием 3.1 - на 62 млн ед. В Евросоюзе объем парка легковых автомобилей достигает пика к 2027 г. (277 млн ед.), затем снижается до 79 млн (на 70\% меньше, чем в 2017 г.); в Китае он достигает пика к 2030 г. (389 млн, затем снижается до 129 млн ед. (на 29\% меньше). При принятых гипотезах распространения электромобилей (см. табл. 1) в сценарии 3.2 к 2045 г. их доля в Евросоюзе составит 34\% (27 млн, в Китае $-28 \%$ (36 млн ед.).

Результаты расчетов в рамках этого сценария для Евросоюза и Китая представлены на рисунках 4 и 5. 


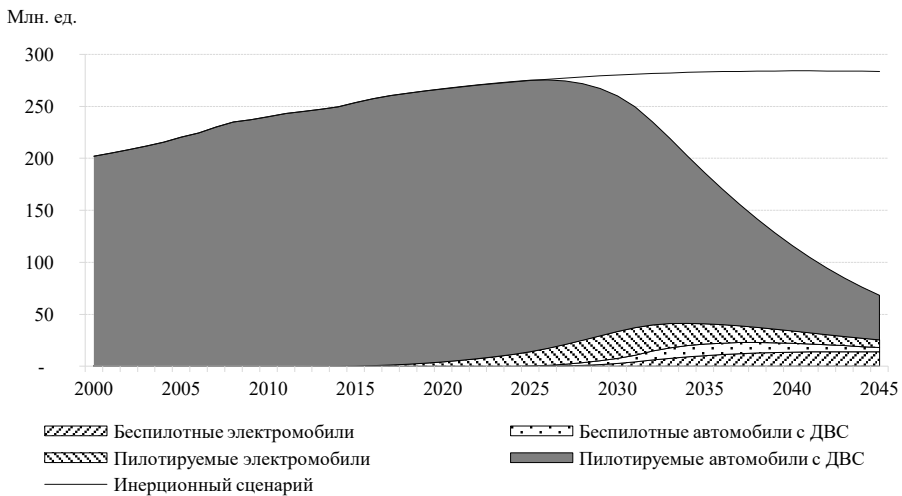

Puc. 4. Динамика и структура парка легковых автомобилей в Евросоюзе в сценарии 3.2 в 2000-2045 гг., млн ед.

Млн. ед.

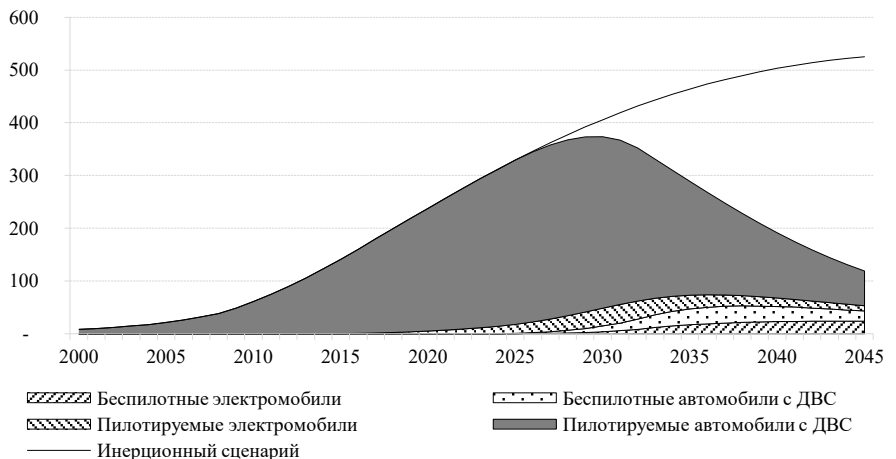

Puc. 5. Динамика и структура парка легковых автомобилей в Китае в сценарии 3.2 в 2000-2045 гг., млн ед.

\section{Сиенарий 4.1 (транспортный коллапс)}

Как и в сценариях 3.1 и 3.2 принимается гипотеза, что внедрение полностью автономных автомобилей начинается в 2025 г., они будут продаваться не только компаниям, но и в личное пользование домохозяйств и использоваться совместно, однако государственные и городские власти не проводят интермодальную транспортную политику, в результате легковой транспорт дополняет общественный, а не заменяет его.

Естественным следствием этой гипотезы является то, что основной спрос на беспилотные автомобили будет формироваться 
пользователями общественного транспорта. Это обосновано следующими соображениями. Во-первых, беспилотный транспорт может быть значительно более экономичным по сравнению с традиционным. В рамках систем каршеринга его экономичность вызвана тем, что не надо оплачивать труд водителя, внутри домохозяйств - тем, что можно содержать один автомобиль вместо двух. В этих условиях общественный транспорт может потерять свою привлекательность. Даже будучи несколько более дорогим по сравнению с общественным транспортом, беспилотный автомобиль предоставляет принципиально иной уровень комфорта, делает поездку индивидуализированной. Уже сейчас некоторые опросы фиксируют замещение использования общественного транспорта (а также - велосипеда, пешей ходьбы) услугами сервисов совместного использования легковых автомобилей [Ализар, 2018]. Во-вторых, в отсутствие интермодальной политики не будут проводиться меры по стимулированию использования общественного транспорта (улучшение его качества, доступности и престижа) и дестимулированию применения легковых автомобилей (административные и финансовые ограничения). В условиях, когда основной спрос на услуги беспилотных совместно используемых автомобилей формируется со стороны пользователей традиционного общественного транспорта, естественно ожидать высоких темпов роста распространения беспилотников. Но степень замещения традиционных легковых автомобилей будет низкой, ведь только часть продаваемых беспилотных автомобилей замещает традиционные легковые, основная их масса замещает общественный транспорт.

В рамках принятых гипотез расчеты показывают, что замещение беспилотниками традиционного общественного транспорта приводит к росту совокупного парка легковых автомобилей в Евросоюзе по сравнению со сценарием 1 на 145 млн по сравнению со сценарием 3.1 - на 258 млн ед.; росту совокупного парка легковых автомобилей в Китае по сравнению со сценарием 1 на 226 млн со сценарием 3.1 - на 561 млн ед. К 2045 г. в Евросоюзе объем парка легковых автомобилей возрастает до 376 млн (на 44\% больше, чем в 2017 г.); в Китае - до 751 млн ед. (в 4,2 раза больше). При принятых гипотезах распространения электромобилей (см. табл. 1) в сценарии 4.1 к 2045 г. их доля в Евросоюзе составит 53\% (198 млн, в Китае - 38\% (286 млн ед.). 


\section{Таблица 6. Численное значение параметров в сценарии 4.1} в 2025 r., 2035 r., 2045 r.

\begin{tabular}{|l|c|c|c|}
\hline \multicolumn{1}{|c|}{ Параметр } & $\mathbf{2 0 2 5}$ & $\mathbf{2 0 3 5}$ & $\mathbf{2 0 4 5}$ \\
\hline $\begin{array}{l}\text { Доля беспилотныхсовместноиспользуемыхавтомобилей } \\
\text { в продажах в 2025 г.,\% }\end{array}$ & 3 & & \\
\hline $\begin{array}{l}\text { Темпы прироста продаж беспилотных совместно исполь- } \\
\text { зуемых автомобилей,\% }\end{array}$ & 80 & 20 & 5 \\
\hline Степень замещения & 0 & 0 & 1 \\
\hline Выбытие традиционных автомобилей,\% & 7 & 7 & 7 \\
\hline
\end{tabular}

Результаты расчетов в рамках этого сценария для Евросоюза и Китая представлены на рисунках 6 и 7.

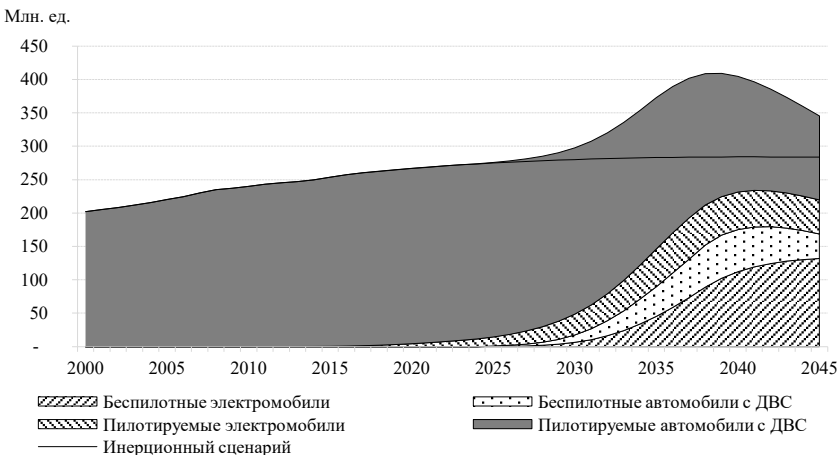

Puc. 6. Динамика и структура парка легковых автомобилей в Евросоюзе в сценарии 4.1 в 2000-2045 гг., млн ед.

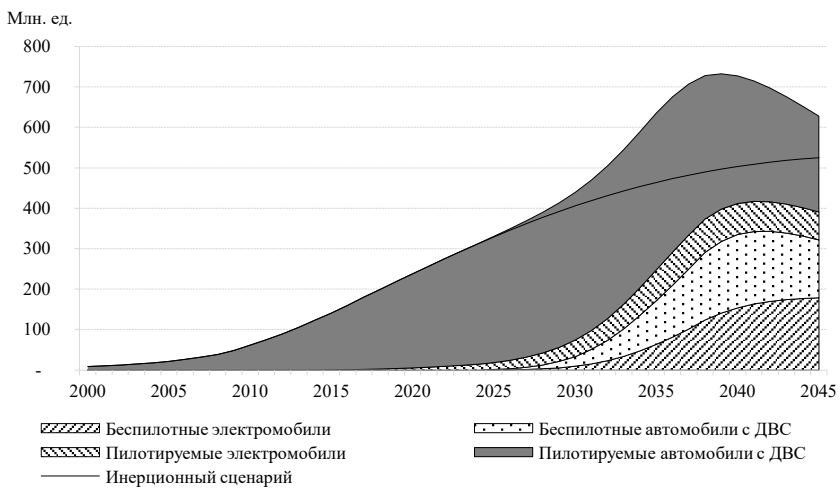

Puc. 7. Динамика и структура парка легковых автомобилей в Китае в сценарии 4.1 в 2000-2045 гг., млн ед. 


\section{Сценарий 4.2 (отставание транспортной политики)}

Основной гипотезой, отличающей сценарий 4.2 от сценария 4.1, является предположение о том, что интермодальная транспортная политика проводится, но отстает от внедрения новых технологий. Это предопределяет на начальном этапе отсутствие существенных препятствий для перетока пассажиров общественного транспорта в сферу совместного использования беспилотных автомобилей. Также предполагается, что беспилотные автомобили, помимо комфортности и индивидуализированности, обладают конкурентным преимуществом по отношению к традиционному общественному транспорту за счет удельной стоимости поездки. Таким образом, в сценарии 4.2 на начальном этапе (2025-2035 гг.) спрос на беспилотные совместно используемые автомобили (как такси, так и в собственности домохозяйств) будет преимущественно формироваться со стороны пользователей общественного транспорта.

По мере возникновения отрицательных последствий описанного процесса (пространственные и экологические проблемы) у государственных и городских властей появится жесткая необходимость выстраивания интермодальной транспортной политики и разработки ряда мер по повышению привлекательности общественного транспорта по сравнению с использованием беспилотных автомобилей. Это должно, с одной стороны, снизить дополнительный спрос на беспилотники, формируемый со стороны пользователей общественного транспорта, с другой повысить степень замещения традиционных автомобилей в связи с тем, что преимущественно новый спрос будет создаваться автомобилистами.

Таким образом, в сценарии 4.2 рассматриваемая перспектива делится на два этапа. На начальном (2025-2035 гг.) гипотезы аналогичны заложенным в сценарии 4.1: высокие темпы роста продаж беспилотных автомобилей предопределяются значительным дополнительным спросом со стороны пользователей общественного транспорта, низкая степень замещения - тем, что только часть продаваемых беспилотников замещает традиционные легковые автомобили, а основная их масса - общественный транспорт. На втором этапе (2035-2045 гг.) предполагается снижение темпов роста рынка беспилотных автомобилей и увеличение степени замещения традиционных автомобилей беспилотными. 
Таблица 7. Численное значение параметров в сценарии 4.2 в 2025 r., 2035 r., 2045 r.

\begin{tabular}{|l|c|c|c|}
\hline \multicolumn{1}{|c|}{ Параметр } & $\mathbf{2 0 2 5}$ & $\mathbf{2 0 3 5}$ & $\mathbf{2 0 4 5}$ \\
\hline $\begin{array}{l}\text { Доля беспилотных совместно используемых автомобилей } \\
\text { в продажах в 2025 г.,\% }\end{array}$ & 3 & & \\
\hline $\begin{array}{l}\text { Темпыприростапродажбеспилотныхсовместноиспользуемых } \\
\text { автомобилей,\% }\end{array}$ & 80 & 15 & 0 \\
\hline Степень замещения & 0 & 1 & 3 \\
\hline Выбытие традиционных автомобилей,\% & 7 & 8 & 10 \\
\hline
\end{tabular}

Расчеты по сценарию 4.2 показывают, что интермодальная транспортная политика, даже значительно отстающая по скорости от изменений в сфере использования легковых автомобилей, способна существенно повысить интенсивность замещения традиционных автомобилей беспилотниками, что приводит к снижению совокупного парка легковых автомобилей в Евросоюзе по сравнению со сценарием 1 на 100 млн, со сценарием 4.1 - на 193 млн ед. Совокупный парк легковых автомобилей в Китае уменьшится по сравнению со сценарием 1 на 203 млн, со сценарием 4.1 - на 429 млн ед. В Евросоюзе объем парка легковых автомобилей достигает пика к 2033 г. (307 млн, затем снижается до 183 млн ед. (на 30\% меньше, чем в 2017 г.); в Китае он достигает пика к 2035 г. (493 млн, затем снижается до 322 млн ед. (на 78\% больше). В принятых гипотезах распространения электромобилей (см. табл. 1) в сценарии 4.2 к 2045 г. их доля в Евросоюзе составит 47\% (87 млн, в Китае $-36 \%$ (116 млн ед.).

Еще одной важной иллюстрацией различий в ходе процессов автомобилизации в сценариях 1-4.2 является динамика показателя числа легковых автомобилей на 1000 человек в ретроспективе и перспективе для КНР (рис. 8) и ЕС (рис. 9).

Кривая, соответствующая сценарию 1, является S-образной, используемой обычно при моделировании динамики автомобилизации в рамках традиционного подхода и обеспечивающей перенос на прогнозную перспективу тех факторов и механизмов, которые определяли ход процессов автомобилизации в ретроспективе. Кривые, соответствующие сценариям 2-4.2, учитывают возможную трансформацию логики процесса автомобилизации при разных вариантах распространения феномена совместного использования и технологий автоматизации вождения. В обоих 
случаях прогнозные оценки, полученные с учетом этих факторов, значительно отклоняются от траектории, полученной в рамках традиционного подхода.

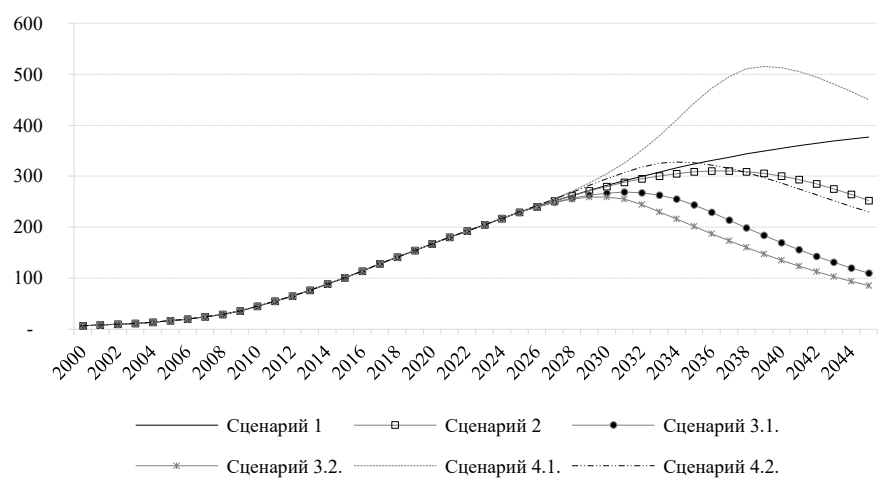

Puc. 8. Число легковых автомобилей на 1000 чел. в Китае в сценариях 1-4.2 в 2000-2044 гг., ед.

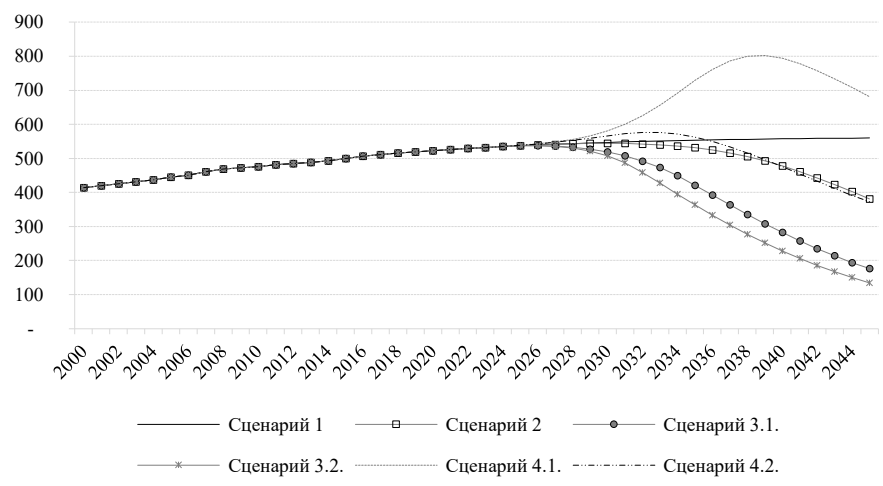

Puc. 9. Число легковых автомобилей на 1000 чел. в Евросоюзе в сценариях 1-4.2 в 2000-2044 гг., ед.

\section{Заключение}

В статье рассмотрен подход к исследованию перспектив автомобилизации, в рамках которого существенное внимание было уделено оценке эффектов, обусловленных распространением новых автотранспортных технологий (автоматизация вождения) и новых моделей потребительского поведения (совместное 
использование автомобилей). Показано, что представления о динамике парков легковых автомобилей и уровней обеспеченности ими населения принципиально отличаются от полученных на основе традиционной парадигмы. В сценарии 3.2, в котором совместно действуют сразу несколько условий, способствующих более интенсивному проникновению беспилотников (возможность покупать их в личное пользование) и замещению ими традиционных автомобилей (интермодальная политика властей, распределение мобильности в течение дня), в долгосрочной перспективе ключевые показатели автомобилизации оказываются многократно ниже их фактических отчетных уровней. Вместе с тем могут быть предложены сценарии (например, 4.1), в которых оценки совокупного парка существенно превышают аналогичные оценки, характерные и для ретроспективы, и для инерционного сценария (прогноза на основе традиционного подхода).

С большой вероятностью логика процессов автомобилизации в ближайшие 10-15 лет может существенно измениться под действием новых технологических и социальных факторов. Следовательно, актуально критическое переосмысление традиционной парадигмы исследований в этой области, которое позволит охватить более широкий спектр траекторий показателей парков и обеспеченности, рисков и возможностей развития сопряженных отраслей экономики.

Сценарии развития автомобилизации играют важную роль не только в контексте транспортной проблематики, но и при прогнозировании спроса на энергоресурсы со стороны автомобильного транспорта, а также при оценке его экологического «следа». Для России существенные изменения в динамике процессов автомобилизации в глобальном масштабе могут стать источником рисков для наращивания или поддержания экспорта нефти и нефтепродуктов, других энергоресурсов. Кроме того, есть основания полагать, что аналогичные процессы в сфере автомобилизации будут происходить и в нашей стране (вероятно, с некоторым запаздыванием). Это может предопределять изменения в динамике и структуре спроса на моторное топливо не только на внешних рынках, но и на внутреннем. С учетом той роли, которую нефтегазовый сектор и ТЭК в целом играют в социально-экономическом развитии нашей страны, новые 
прогнозно-аналитические сюжеты, позволяющие конструктивно рассмотреть широкий спектр альтернатив развития процессов автомобилизации, должны быть проанализированы не только в контексте энергетической политики, но и при обосновании стратегии структурно-технологической модернизации национальной экономики.

\section{Литература/References}

Ализар A. Удобные сервисы вроде Uber усугубляют автомобильные пробки, отбирая пассажиров у общественного транспорта // Geektimes, 27.02.2018. [Эл. pecypc]. URL: https://geektimes.ru/post/298599/ (дата обращения: 23.03.2018). [Alizar A. Udobnye servisy vrode Uber usugubljajut avtomobil'nye probki, otbiraja passazhirov u obschestvennogo transporta. Available at https://geektimes.ru/ post/298599/ (accessed 23.02.2018) (In Russ.)]

Анисимов Г. Еврокомиссия стимулирует переход на электромобили // Ведомости. 2017. 9 нояб. [Эл. ресурс]. URL: https://www.vedomosti.ru/auto/ articles/2017/11/09/741050-perehod-elektromobili (дата обращения: 28.02.2018). [Anisimov G. Evrokomissiya stimuliruet perehod na elektromobili. Vedomosti. Available at https://www.vedomosti.ru/auto/articles/2017/11/09/741050-perehodelektromobili (accessed 28.02.2018). (In Russ.)]

Вучик B.P. Транспорт в городах, удобных для жизн Problemy prognozirovaniya / Пер. с англ. А. Калинина под науч. ред. М. Блинкина.: Территория будущего. М., 2011. С. 576. [Vuchik V.R.(2011) Transport v gorodah, udobnyh dlya zhizn Problemy prognozirovaniyai. In: Territoriya budushego. Moscow. P. 576.(In Russ.)]

Дорога в будущее: понять автомобилиста завтрашнего дня. Анализ автономных транспортных средств, встроенных в автомобиль технологий, систем каршеринга и райдшеринга в США // PricewaterhouseCoopers, 2018. [Эл. реcypc]. URL: https://www.pwc.ru/ru/publications/driving-the-future/PWC_AutoTech_ russian_Eversion.pdf (дата обращения: 28.04.2018).

Ксенофонтов М.Ю., Милякин С. Р. Процесс автомобилизации и определяющие его факторы в ретроспективе, настоящем и будущем// Проблемы прогнозирования. 2018. № 4. C. 92-105. [Ksenofontov M. Yu., Milyakin S.R. (2018) Process avtomobilizacii i opredelyayushie ego faktory v retrospektive, nastoyashem i budushem. Problemy prognozirovaniya. [Problems of Forecasting] No.4. Pp. 92-105. (In Russ.)]

Эдер Л.В., Немов В.Ю. Прогнозирование потребления энергии легковым автомобильным транспортом // Проблемы прогнозирования. 2017. № 4. C. 83-93. [Eder L. V., Nemov V. Yu. (2017) Prognozirovanie potrebleniya energii legkovym avtomobilnym transportom. Problemy prognozirovaniya. [Problems of Forecasting] No. 4. Pp. 83-93.(In Russ.)]

Эткин Д. Возможный подход к прогнозированию объема продаж массовых автомобилей (на примере авторынка США) // Проблемы прогнозирования. 2009. № 1. C. 132-143. [Etkin D. (2009) Vozmozhnyj podhod k prognozirovaniyu obema prodazh massovyh avtomobilej (na primere avtorynka SShA). Problemy prognozirovaniya. [Problems of Forecasting] No.1. Pp.132-143. (In Russ.)] 
Jong G., Fox J., Andrew Daly, Pieters M., Smit R. (2004). Comparison of car ownership models. A Transnational Transdisciplinary Journal. Vol. 24. No. 4. Pp. 379-408.

Tanner J. C. (1975). Forecasts of vehicles and traffic in Great Britain: 1974 revision. Department of the Environment, Transport and Road Research Laboratory, TRRL Laboratory Report 650.

Debabrata D., Subhash D., Sharifuddin. (2010). Car ownership growth in Delphi. Decision. Vol. 37. No. 2. Pp. 51-61.

Dargay J., Gately D., Sommer M. (2007). Vehicle Ownership and Income Growth, Worldwide: 1960-2030. The Energy Journal. Vol. 28. No. 4. Pp. 143-170.

Hao H., Wang H., Yi R. (2011). Hybrid modeling of China's vehicle ownership and projection through 2050. Energy. Vol. 36. No. 2. Pp. 1351-1361.

Wu T., Zhao H., Ou X. (2014). Vehicle Ownership Analysis Based on GDP per Capita in China: 1963-2050. Sustainability. Vol. 6. No. 8. Pp. 4877-4899.

Button K. J., Hine J., Ngoe N. (1993) Modelling vehicle ownership and use in low-income countries. Journal of Transport and Policy. Vol. 27. No. 1. Pp. 51-67.

Tanner J.C. (1977). Car ownership trends and forecasts. Department of the Environment, Transport and Road Research Laboratory, TRRL Laboratory Report 799.

Tanner J. C. (1983). A lagged model for car ownership forecasting. Department of the Environment, Transport and Road Research Laboratory, TRRL Laboratory Report 1072.

Goodwin P. (2012). Peak Travel, peak car and the future of mobility: Evidence, Unresolved Issues, Policy Implications, and a Research Agenda. International Transport Forum, Discussion Paper. No. 2012/13. P. 41.

Arbib J., Seba T. (2017). Rethinking Transportation 2020-2030: The Disruption of Transportation and the Collapse of the Internal-Combustion Vehicle and Oil Industries. A RethinkX Sector Disruption Report. Available at: http://www.rethinkx. com/transportation/ (accessed 28.02.2018).

Hawksworth J., Berriman R., Goel S. (2018) Will robots really steal our jobs?: An international analysis of the potential long term impact of automation. PricewaterhouseCoopers. P. 47. Available at: https://www.pwc.co.uk/economicservices/assets/international-impact-of-automation-feb-2018.pdf (accessed 28.02.2018).

Shaheen S., Cohen A., Jaffee M. (2018). Innovative Mobility: Carsharing Outlook. California Digital Library, University of California, P: 8. Available at: https:/cloudfront.escholarship.org/dist/prd/content/qt1mw8n13h/qt1mw8n13h. pdf? $\mathrm{t}=\mathrm{p} 5$ wqud (accessed 28.02.2018).

Marshall A. (2017). After Peak Hipe, Self-Driving Cars Enter the Trough of Disillusionment. Wired. Available at: https://www.wired.com/story/self-driving-carschallenges/ (accessed 28.02.2018).

Lenardi M. (2017) The future of driverless cars in Europe. Hitache. Available at: http:/www.hitachi.eu/en/social-innovation-stories/transport/future-driverless-carseurope (accessed 28.02.2018).

Brodsky J. S. (2016). Autonomous Vehicle Regulation: How an Uncertain Legal Landscape May Hit The Brakes on Self-Driving Cars. Berkeley Technology Law Journal. Vol. 31. No. 2. Pp. 851-877. 
Grush B., Niles J., Baum E. (2016). Ontario Must Prepare for Vehicle Automation: Automated vehicles can influence urban form, congestion and infrastructure delivery. Residential and Civil Construction Alliance of Ontario. P. 76.

Higgins T., Spector M., Colias M. (2018). Tesla, Uber deaths raise questions about the perils of partly autonomous driving. Wall Street Journal. Available at: https://www.wsj.com/articles/tesla-uber-deaths-raise-questions-about-the-perils-ofpartly-autonomous-driving-1522661400 (accessed 28.02.2018).

Kurman M., Lipson H. (2018). Why the rise of self-driving vehicles will actually increase car ownership. SingularityHub. Available at: https://singularityhub. com/2018/02/14/why-the-rise-of-self-driving-vehicles-will-actually-increase-car-ow nership/\#sm.00001w23437829djxttku2r13oqmg (accessed 28.02.2018).

Статья поступила 19.07.2018.

\section{Summary}

Ksenofontov M. Yu., Milyakin S.R., Institute of Economic Forecasting RAS, Moscow

Perspective of Motorization in the European Union and China in Various Scenarios of Diffusion of Fully Autonomous Shared Automobiles

The article is devoted to the forecast of car fleet trends in various scenarios of the diffusion of the car-sharing phenomenon and automated driving technologies. The description of scenarios, tools of variant scenario forecast calculations, as well as their results for the European Union and China are given. They demonstrate that in the 25-30 years perspective, these social and technological innovations can have a significant impact on the trajectory of car ownership and total car fleet. Under the influence of new factors, trends in these indicators will be described by a curve that has a «peak», i.e. the maximum value, after which it will be observed not the stabilization of the achieved levels, as in the framework of the traditional approach for motorization processes modeling using S-shaped functions, but a grand-scale decline.

Motorization; car-sharing; autonomous vehicles; scenario calculations; longterm forecast 